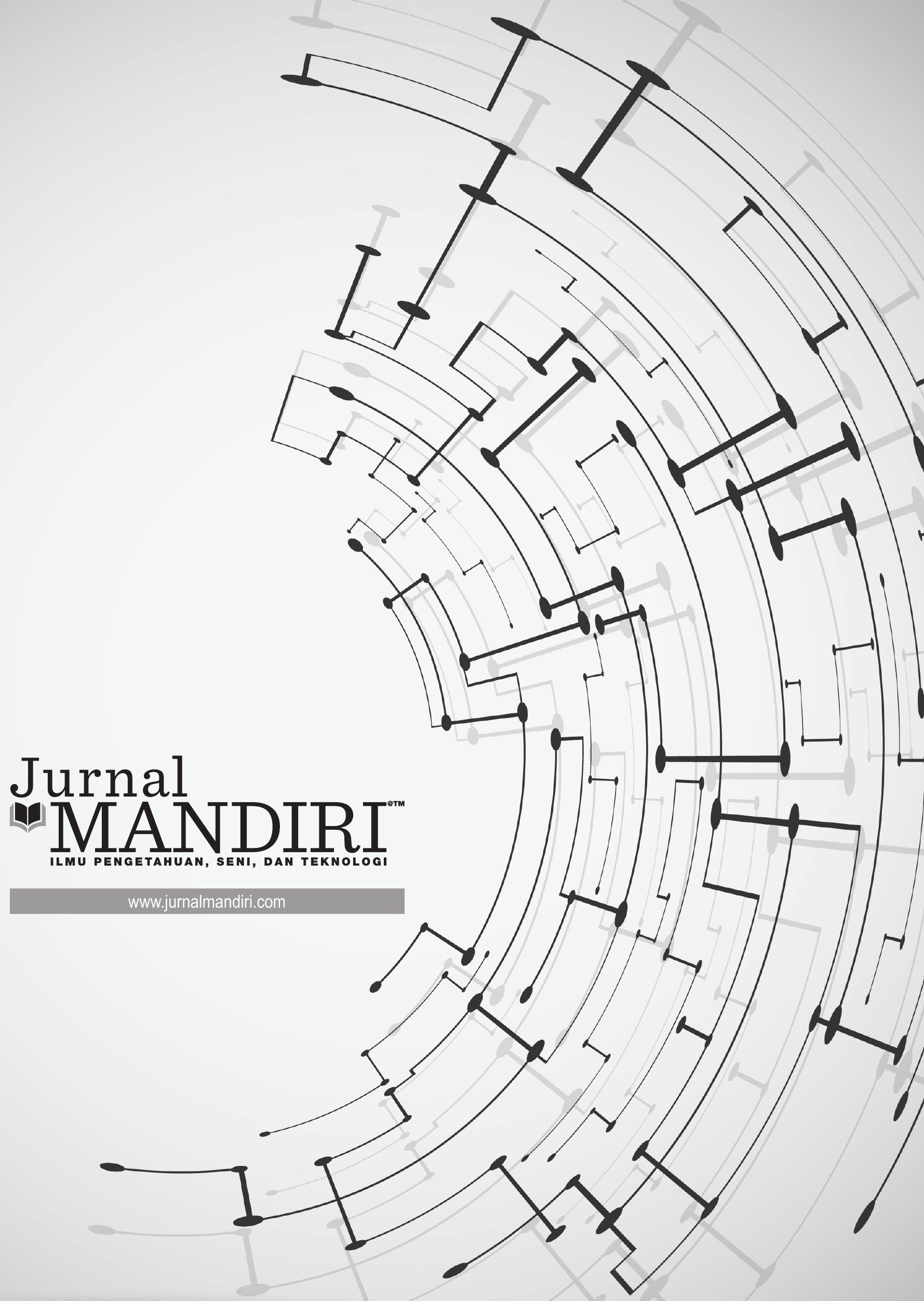


ISSN : 2580-3220, E-ISSN : 2580-4588

J. Mandiri., Vol. 4, No. 1, Juni 2020 (14 - 25)

C2018 Lembaga Kajian Demokrasi

dan Pemberdayaan Masyarakat (LKD-PM)

DOI : https://doi.org/10.33753/mandiri.v4i1.96

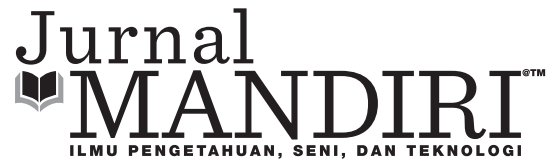

\title{
Strategi Peningkatan Kinerja Dosen Melalui Pengembangan Dimensi Modal Sosial Pada Perguruan Tinggi Swasta \\ (Studi Kasus Perguruan Tinggi Swasta di Kota Serang)
}

\author{
Uli Wildan Nuryanto \\ Program Studi Doktoral Ilmu Manajemen, Universitas Mercu Buana \\ uli.wildan11@gmail.com \\ Masyhudzulhak Djamil \\ Program Studi Doktoral Ilmu Manajemen, Universitas Mercu Buana \\ masydk@gmail.com \\ Achmad H. Sutawidjaya \\ Program Studi Doktoral Ilmu Manajemen, Universitas Mercu Buana \\ suta.phd@gmail.com \\ A. Badawi Saluy \\ Program Studi Doktoral Ilmu Manajemen, Universitas Mercu Buana \\ badawi_saluy@yahoo.co.id
}

\begin{abstract}
Abstrak
Peran perguruan tinggi dalam mempersiapkan sumber daya manusia yang berkualitas dan handal tidak dapat dilepaskan dari kinerja dosen. Mengingat peran, tugas dan tanggung jawab dosen sangat penting dalam mendidik mahasiswanya. Dengan masih kentalnya budaya bahwa dosen merupakan aktor utama didalam kelas yang bertanggung jawab penuh terhadap penyampaian materi ditambah dengan tugas tri dharma lainnya seperti penelitian dan pengabdian masyarakat belum lagi ditambah dengan tugas lainnya yang menjadikan beban kerja dosen dari segi administratif sangat menguras waktu serta energi. Kecenderungan ini akan menyebabkan adanya gap antara dosen akibat kesibukan masing-masing dosen yang menyebabkan hubungan antara dosen menjadi tidak maksimal dan cenderung menimbulkan rasa individualisme serta berpengaruh terhadap kinerjanya, sehingga diperlukan pendekatan sosial dalam menjembatani hal tersebut. Untuk itulah penelitian ini dilakukan untuk membuktikan adanya hubungan pengaruh dari dimensi modal sosial yang terdiri dari dimensi struktural, dimensi rasional dan dimensi kognitif terhadap kinerja dosen. Penelitian dilakukan pada salah satu perguruan tinggi swasta di Kota Serang, terhadap 58 dosen tetap dengan menggunakan metode purposive sampling dan metode analisis Partial Least Square. Hasil penelitian menunjukkan bahwa ketiga dimensi memiliki hasil outer model analysis dan inner model analysis yang fit dan berpengaruh signifikan baik secara parsial maupun simultan, dengan besarnya pengaruh total sebesar 72,8\% sedangkan sisanya sebesar 27,2\% dipengaruhi variabel diluar model penelitian ini. Dimensi kognitif menjadi dimensi yang paling dominan dari variabel modal sosial terhadap kinerja dosen.
\end{abstract}

Kata Kunci : Modal Sosial, Dimensi Struktural, Dimensi Relasional, Dimensi Kognitif, Kinerja Dosen

\section{Abstract}

The role of universities in preparing quality and reliable human resources cannot be separated from lecturer performance. Given the role, duties and responsibilities of lecturers is very important in educating students. 
With the still thick culture where the lecturers as main actors in the classroom who are fully responsible for the delivery of material, coupled with other tridharma assignments such as research and community service not to mention added with other tasks that make the administrative workload of lecturers very draining time and energy. This tendency will cause gaps between lecturers due to the busyness of each lecturer which causes the relationship between lecturers to be suboptimal and tends to create a sense of individualism and affect their performance, so a social approach is needed to bridge this. For this reason, the research conducted to test the influence relationship between social capital dimensions consisting of structural dimensions, rational dimensions and cognitive dimensions on lecturer performance. The study was conducted at one private university in the city of Serang, against 58 permanent lecturers using the purposive sampling method and the Partial Least Square analysis method. The results showed that the three dimensions had the results of an outer model analysis and inner model analysis that were fit and had a significant effect both partially and simultaneously, with a total influence of $72.8 \%$ while the remaining $27.2 \%$ were influenced by variables outside this research model. Cognitive dimension becomes the most dominant dimension of social capital variables on lecturer performance.

Keywords : Social Capital, Structural Dimensions, Relational Dimensions, Cognitive Dimensions, Lecturer Performance

\section{PENDAHULUAN}

Dalam era globalisasi saat ini, peran perguruan tinggi dalam meningkatkan kesejahteraan masyarakat sangat dibutuhkan. Salah satu peran dari perguruan tinggi adalah dengan meningkatkan kualitas pendidikan dalam mencetak sumber daya manusia yang unggul dan berkualitas. Dengan peran tersebut diharapkan mahasiswa akan menjadi garda terdepan dalam mengisi pembangunan nasional sehingga roda perekonomian dapat berjalan dengan maksimal dan mampu bersaing dalam menghadapi persaingan pasar bebas yang memiliki empat ciri antara lain: kawasan ekonomi yang sangat kompetitif, memiliki wilayah pembangunan ekonomi yang merata, daerah-daerah akan terintegrasi secara penuh dalam ekonomi global serta adanya basis dan pasar produksi tunggal.

Dengan adanya ciri khas pasar bebas tersebut maka satu-satunya cara agar ekonomi nasional mampu bertahan dan bahkan meningkat adalah dengan meningkatkan kemampuan daya saing. Untuk meningkatkan daya saing maka Indonesia harus bertumpu kepada SDM yang inovatif dan kreatif, dalam artian harus memiliki SDM yang mampu berinovasi sehingga dapat memegang peran dalam mengembangkan produk dan jasa dalam bisnis. Mengingat kesuksesan besar di dunia hanya akan mampu didorong oleh daya kreativitas yang tinggi. Kesemuanya itu hanya terwujud jika perguruan tinggi sebagai lembaga penyelenggara pendidikan tinggi mampu mendidik putra-putri bangsa agar menguasai iptek sekaligus juga mempersiapkan calon-calon pemimpin bangsa.

Pencapaian perguruan tinggi dalam mencetak putra-putri bangsa menjadi garda terdepan dalam pembangunan bangsa tidak akan bisa dilepaskan dari peran dosen. Mengingat dosen merupakan salah satu komponen esensial dalam sistem pendidikan di perguruan tinggi. Untuk itulah peran, tugas dan tanggung jawab dosen sangat vital bagi peningkatan sumber daya manusia yang berkualitas. Kinerja dosen tidak hanya didukung oleh kompetensi dan profesionalisme, melainkan juga oleh modal sumber daya manusia yang dapat mempersatukan keanekaragaman yang cukup tinggi diantara pegawainya yaitu dalam bentuk modal sosial.

Sesuai dengan pembukaan (Undang-Undang Republik Indonesia No. 14 Tahun 2005. Tentang Guru dan Dosen) bagian c menyebutkan bahwa guru dan dosen mempunyai fungsi, peran dan kedudukan yang sangat strategis dalam pembangunan nasional dalam bidang pendidikan. Selanjutnya jika mengikuti pasal 3 ayat 1 maka fungsi dan peran dosen sebagai tenaga profesional berfungsi untuk meningkatkan martabat dan peran sebagai agen pembelajaran, pengembangan ilmu pengetahuan, teknologi dan seni, serta pengabdian masyarakat yang berfungsi untuk meningkatkan mutu pendidikan nasional. Hal 
tersebut diperjelas pada pasal 60 sesuai dengan tugas pokok dan fungsi dosen yang memiliki enam kewajiban pokok diantaranya adalah; (1) Melaksanakan Pendidikan, penelitian dan pengabdian pada masyarakat, (2) merencanakan, melaksanakan proses pembelajaran serta menilai dan mengevaluasi hasil pembelajaran, (3) meningkatkan dan mengembangkan kualifikasi akademik dan kompetensi secara berkelanjutan sejalan dengan perkembangan ilmu pengetahuan, teknologi dan seni, (4) bertindak objektif dan tidak diskriminatif atas dasar pertimbangan jenis kelamin, agama, suku, ras dan kondisi fisik tertentu atau latar belakang sosial ekonomi peserta didik dalam pembelajaran, (5) menjunjung tinggi peraturan perundang-undangan, hukum, kode etik serta nilai-nilai agama dan etika, dan (6) memelihara dan memupuk persatuan dan kesatuan bangsa.

Eksistensi dari suatu modal sosial merupakan bangunan hubungan sosial yang didasari dengan kepercayaan sehingga mampu membangkitkan semangat kebersamaan atau dapat diistilahkan dengan solidaritas sosial. Dengan adanya modal sosial maka mampu menumbuhkan suatu perilaku positif yang dapat mendorong individu untuk berperilaku lebih baik demi tercapainya tujuan bersama yang telah ditetapkan. Berdasarkan hasil wawancara yang telah dilakukan dalam forum discussion group yang dilakukan disalah satu perguruan tinggi swasta di Kota Serang, disimpulkan bahwa tuntutan yang wajib dijalankan oleh dosen dalam menjalankan fungsi tridharma akan sangat terbantu apabila terdapat rasa solidaritas diantara dosen sehingga dapat menimbulkan rasa saling mempercayai (trust) dalam berinteraksi sosial sehingga akan berdampak terhadap keinginan untuk saling berpartisipasi dan terdapat proses timbal balik yang saling membangun.

Kinerja atau performance dalam konteks tugas sama dengan prestasi kerja. Pengertian kinerja dapat diartikan sebagai penampilan hasil karya personel baik kuantitas maupun kualitas dalam suatu organisasi (Simamora, 2014). Sedangkan Simanjuntak (2005) mengemukakan kinerja adalah tingkat pencapaian hasil dalam rangka mewujudkan tujuan organisasi. Adapun prestasi kerja berasal dari kata job performance atau hasil kerja yang secara kualitas dapat dicapai oleh seorang pegawai dalam melaksanakan tugas dan tanggung jawabnya (Mangkunegara, 2001). Berdasarkan pendapat tentang kinerja tersebut maka dapat disimpulkan bahwa kinerja mengandung substansi sebagai pencapaian hasil kerja oleh seseorang. Adapaun kaitannya dengan perguruan tinggi, kinerja dosen menjadi salah satu faktor penentu keberhasilan proses belajar mengajar pada perguruan tinggi. Pramudyo (2010) mengemukakan bahwa terdapat hubungan yang era tantara kinerja perseorangan dengan kinerja perguruan tinggi, sehingga dalam hubungannya dengan kinerja dosen sebagai salah satu elemen dalam perguruan tinggi dapat disimpulkan bahwa peningkatan kinerja dosen dapat meningkatkan kinerja perguruan tinggi.

Modal sosial didefinisikan secara bervariasi dan salah satu definisi yang popular yang dikemukakan oleh (Putnam, 1993): "social capital refers to features of social organizations, such as trust, norms, and networks", bahwa sosial kapital didefinisikan sebgai rasa percaya, norma timbal balik dan jaringan sosial. Atribut ini yang memungkinkan para partisipan bertindak bersama secara lebih efektif untuk mencapai tujuan bersama (Khoirrini \& Kartika, 2016). Modal sosial merupakan segala sesuatu yang berkaitan dengan kerja sama dalam masyarakat atau bangsa untuk mencapai tujuan hidup yang lebih baik, yang ditopang dengan nilai-nilai dan norma yang menjadi unsur-unsur utama seperti trust (rasa saling mempercayai), partisipasi masyarakat, proses timbal balik, aturan-aturan kolektif dalam suatu masyarakat atau bangsa dan sejenisnya. Salah satu unsur yang diperlukan dalam kelompok adalah sifat dan sikap untuk saling percaya dan bisa dipercaya dalam hubungan kerjasama sehingga diantara anggota kelompok memiliki tingkat kepercayaan yang tinggi. Kepercayaan merupakan modal yang sangat penting untuk membangun jaringan kemitraan dan kerjasama dengan pihak luar. Kerjasama yang dilandasi dengan kepercayaan akan terjadi apabila dilandasi oleh kejujuran, keadilan, keterbukaan, saling pe- 
duli, saling menghargai dan saling menolong diantara anggota kelompok.

Modal sosial yang kuat akan meningkatkan keefektifan suatu kelompok dalam mencapai tujuan dan mengurangi tekanan di dalam kelompok karena setiap anggota merasa nyaman berada di dalam kelompoknya (Pratisthita, 2014). Nahapiet dan Ghoshal (1998) dalam Abbasi \& Malik (2015) membagi modal sosial menjadi tiga dimensi yaitu dimensi struktural, dimensi relasional dan dimensi kognitif. Menurut Oliveira, J. F dan Wegner (2013), dimensi struktural dari modal sosial merupakan pola hubungan yang terjadi antara pelaku. Dimensi struktural terdiri dari tiga elemen yaitu jumlah relasi yang dimiliki, kebergaman relasi, dan jabatan atau kekuatan relasi yang dimiliki. Nahapiet dan Ghoshal (1998) dalam Mamun et al. (2015) menyatakan bahwa dimensi struktural menitikberatkan kepada sifat dari sistem sosial dan hubungan jaringan secara keseluruhan. Dimensi relasional lebih menunjukkan karakteristik dari suatu hubungan yang terjadi diantara relasi. Dimensi relasional ini dapat bergantung kepada kualitas hubungan antar relasi. Sebagai contoh mengenai dimensi relasional dapat terlihat apabila membandingkan interaksi antara individu yang memiliki posisi yang sama dalam suatu hubungan seperti halnya hubungan antara pembeli dan penjual. Interaksi antara masing-masing pelaku individu sangat tinggi dipengaruhi oleh hubungan dan sejarah hubungan antar individu tertentu (Muniady et al., 2015). Inti dari dimensi ini adalah kepercayaan, relasi yang dapat diandalkan, tanggung jawab dan feedback yang didapat. Dimensi kognitif menunjukkan banyak unsur kesamaan yang harus ada dalam sebuah hubungan. Elemen-elemen yang terdapat dalam dimensi kognitif meliputi norma-norma kebersamaan, kode tindakan dan kesamaan pandangan (Abbasi \& Malik, 2015).

Banyak organisasi yang menyadari bahwa pentingnya interaksi serta hubungan baik antara pegawai di dalam bekerja. Eksistensi pentingnya modal sosial dalam kinerja begitu penting mengingat dorongan yang ditimbulkan berupa terbentuknya solidaritas dan adanya kesamaan tujuan yang ditunjukkan oleh para pegawai. Hal inilah yang kemudian mendasari peneliti untuk melakukan penelitian terkait konsep modal sosial terhadap kinerja dosen. Astuti (2012) dalam penelitiannya menggunakan dimensi dari modal sosial terhadap kinerja didapatkan hasil bahwa dimensi relasional dan struktural baik secara parsial maupun simultan berpenaruh positif signifikan terhadap kinerja pegawai. Edy et al. (2013) mendapatkan hasil penelitian bahwasanya modal sosial secara parsial berpengaruh positif dan signifikan terhadap terhadap kinerja pegawai. Sedangkan Khoirrini \& Kartika (2016) mendapatkan hasil bahwasanya dimensi relasional merupakan dimensi yang paling disetujui dalam membentuk modal sosial, variabel modal sosial berpengaruh positif dan signifikan baik secara parsial maupun simultan terhadap variabel kinerja. Tjahjaningsih (2016) mendapatkan hasil penelitian bahwasanya modal sosial berpengaruh positif dan signifikan terhadap organizational citizenship behavior (OCB) dan kinerja karyawan.

Hasil penelitian Ghifary (2017) menemukan bahwa structural social capital, relational social capital maupun cognitive social capital secara terpisah mempunyai pengaruh positif yang signifikan terhadap kinerja pegawai. Interaksi sosial, tingkat kepercayaan serta kesamaan dalam mengartikan visi perusahaan dipandang merupakan aspek yang dapat mewarnai kinerja pegawai. Ketika ketiga dimensi ini disatukan maka masih tampak adanya pengaruh terhadap kinerja pegawai. Namun manakala ketiga dimensi tersebut diperlakukan secara multidimensial maka tidak diperoleh hasil keterpengaruhan yang signifikan. Modal sosial sebagai salah satu kesatuan tidak dapat diposisikan pada dimensinya masing-masing, tetapi harus diletakkan sebagai sebuah kerangka dimensi yang utuh. Hartono (2017) dalam penelitannya menyimpulkan bahwa dimensi struktural, dimensi relasional, dan dimensi kognitif dari modal sosial berpengaruh signifikan terhadap kinerja individu. Sedangkan Bangsri et al. (2018) dalam penelitiannya menyimpulkan bahwa modal sosial yang terdiri dari network, trust, dan norm berpengaruh positif dan signifikan terhadap keberlanjutan organisasi dengan besarnya pengaruh sebesar $71,10 \%$. 


\section{METODE}

Penelitian ini dilakukan dengan menggunakan pendekatan kuantitaif dan metode asosiatif kasusal dimana tujuan dari penelitian ini untuk mengetahui pengaruh hubungan antara variabel eksogen terhadap variabel endogen serta indikator-indikator mana saja yang dapat membangun masing-masing variabel. Analisis dilakukan dengan menggunakan Smart PLS 3. Penelitian ini dilakukan pada salah satu perguruan tinggi swasta di Kota Serang dengan jumlah sampel sebanyak 58 orang yang merupakan dosen tetap dan sudah memiliki jabatan fungsional. Penelitian ini menggunakan data primer berupa kuesioner sebagai instrumen penelitian dan menggunakan skala pengukuran Likert dengan angka 1 sampai dengan 5 yang dibagikan secara langsung kepada dosen.

Penelitian ini membagi variabel menjadi dua jenis variabel yaitu variabel eksogen dan variabel endogen. Variabel eksogen terdiri dari tiga dimensi modal sosial yaitu dimensi struktural, dimensi relasional, dan dimensi kognitif. Sedangkan variabel endogen terdiri dari kinerja dosen. Adapun masing-masing indikator yang digunakan pada penelitian ini dapat terlihat pada tabel berikut:

\begin{tabular}{|c|c|c|c|c|}
\hline \multicolumn{5}{|c|}{ Tabel 1. Operasional Variabel Penelitian } \\
\hline No & $\begin{array}{c}\text { Jenis } \\
\text { Variabel }\end{array}$ & Variabel & Indikator & Referensi \\
\hline 1 & Eksogen & $\begin{array}{l}\text { Dimensi } \\
\text { Struktural }\end{array}$ & $\begin{array}{l}\text { 1. Menyelesaikan tugas dengan } \\
\text { baik } \\
\text { 2. Memenuhi tanggung jawab } \\
\text { sesuai job deskripsi } \\
\text { 3. Melaksanakan tugas yang } \\
\text { harus dilakukan } \\
\text { 4. Memenuhi tuntutan kinerja } \\
\text { yang telah ditentukan }\end{array}$ & $\begin{array}{l}\text { Chua, } \\
20021\end{array}$ \\
\hline 2 & Eksogen & $\begin{array}{l}\text { Dimensi } \\
\text { Relasional }\end{array}$ & $\begin{array}{l}\text { 1. Terlibat dalam kegiatan } \\
\text { secara langsung } \\
\text { 2. Bersedia meluangkan waktu } \\
\text { untuk membantu rekan kerja } \\
\text { 3. Bersedia menggantikan } \\
\text { tugas rekan kerja } \\
\text { 4. Berbicara terlebih dahulu } \\
\text { dengan rekan kerja } \\
\text { 5. Berusaha menghindari } \\
\text { terjadinya konflik dengan } \\
\text { rekan kerja }\end{array}$ & $\begin{array}{l}\text { (Chua, } \\
2002 \text { ) }\end{array}$ \\
\hline 3 & Eksogen & $\begin{array}{l}\text { Dimensi } \\
\text { Kognitif }\end{array}$ & $\begin{array}{l}\text { 1. Mengikuti norma-norma } \\
\text { yang berlaku } \\
\text { 2. Setiap tindakan berusaha } \\
\text { untuk menghindari konflik } \\
\text { 3. Memiliki kesamaan tujuan } \\
\text { sesuai dengan visi dan misi } \\
\text { organisasi. }\end{array}$ & $\begin{array}{l}\text { (Abbasi } \\
\text { \& Malik, } \\
\text { 2015) }\end{array}$ \\
\hline 4 & Endogen & $\begin{array}{l}\text { Kinerja } \\
\text { Dosen }\end{array}$ & $\begin{array}{l}\text { 1. Tepat Waktu } \\
\text { 2. Loyalitas } \\
\text { 3. Sesuai Target } \\
\text { 4. Kemauan yang Keras } \\
\text { 5. Kreatif }\end{array}$ & $\begin{array}{c}\text { (Supriadi, } \\
2019 \text { ) }\end{array}$ \\
\hline
\end{tabular}

Adapun kerangka pemikiran penelitian, persamaan serta hipotesis penelitian adalah sebagai berikut:

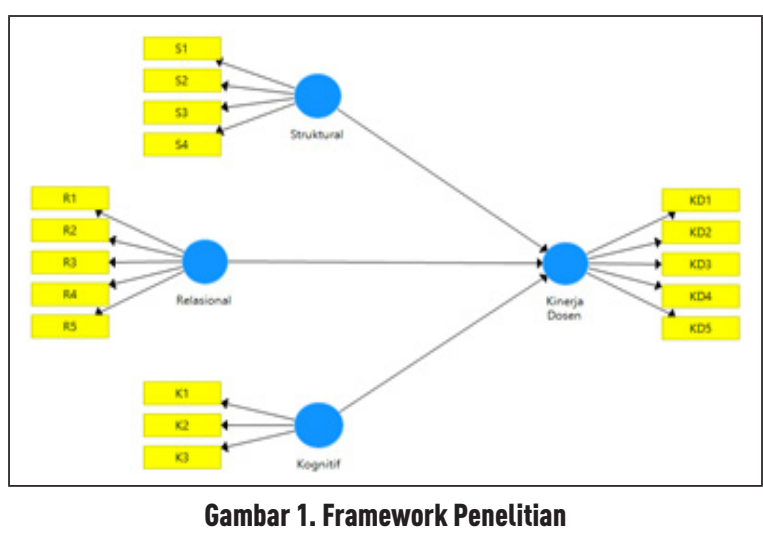

Hipotesis 1 : Dimensi struktural modal sosial secara parsial berpengaruh positif dan signifikan terhadap kinerja dosen

Hipotesis 2 : Dimensi relasional modal sosial secara parsial berpengaruh positif dan signifikan terhadap kinerja dosen

Hipotesis 3 : Dimensi kognitif modal sosial secara parsial berpengaruh positif dan signifikan terhadap kinerja dosen

Hipotesis 4 : Dimensi struktural, relasional dan kognitif secara simultan berpengaruh positif dan signifikan terhadap kinerja dosen.

Secara lebih detail, penelitian ini menggunakan dua pendekatan analisis statistik yaitu analisis deskriptif dan analisis inferensial. Analisis deskriptif dilakukan untuk mengetahui gambaran secara umum tentang objek penelitian dan juga responden secara lebih rinci dengan menggunakan program SPSS Versi 22. Sehingga diharapkan dapat memberikan gambaran data yang dilihat dari frekuensi dan nilai angka indeks. Penelitian ini menggunakan data primer berupa kuesioner, oleh karenanya peneliti melakukan analisis instrumen terlebih dahulu untuk menentukan apakah item kuesioner yang diajukan kepada responden telah valid dan reliabel dengan menggunakan uji validitas dan reliabilitas. Instrumen penelitian menurut (Ferdinand, 
2013) adalah semua alat yang digunakan untuk mengumpulkan, memeriksa, dan menyelidiki suatu masalah atau mengumpulkan, mengolah, menganalisa dan menyajikan data-data secara sistematis serta objektif dengan tujuan memecahkan suatu persoalan atau menguji hipotesis. Penelitian ini menggunakan beberapa macam metode instrumen penelitian, diantaranya adalah wawancara, pengamatan atau observasi, dan angket atau kuesioner. Penelitian yang menggunakan kuesioner mutlak memerlukan uji validasi dan realibilitas. Uji validitas menunjukkan kinerja kuesioner dalam mengukur apa yang diukur.

Untuk menguji validitas kuesioner, peneliti menggunakan alat bantu analisis SPSS dan melakukan uji validitas menggunaan analisa pearson korelasi, dimana hasil nilai korelasi atau nilai $\mathrm{r}_{\text {hitung }}$ dibandingkan dengan $\mathrm{r}_{\text {tabel }}$ jika nilai $\mathrm{r}_{\text {hitung }}$ didapatkan lebih besar dari $\mathrm{r}_{\text {tabel }}$ maka kuesioner dikatakan valid. Analisa lainnya juga dapat digunakan dengan cara membandingkan antara nilai sigifikansi dengan nilai Alpha atau probabilitas 0,05 karena tingkat nilai tingkat ketelitian pada penelitian ini adalah 95\%, sehingga jika nilai signifikansi didapatkan lebih kecil dari 0,05 maka kuesioner dikatakan valid (Hair et al. 2014).

Untuk menguji reliabilitas dari kuesioner penelitian, peneliti menggunakan alat bantu analisis SPSS dan melakukan uji reliabilitas alpha cronbach's, dimana hasl nilai alpha Cronbach's dikatakan reliable jika hasilnya lebih besar dari 0,60 sedangkan jika nilai alpha cronbach's dibawah 0,60 maka kuesioner atau angket dinyatakan tidak reliable atau tidak konsisten. Uji ini dilakukan untuk mengetahui tingkat konsistensi dari angket yang digunakan oleh peneliti, sehingga angket tersebut dapat dihandalkan untuk mengukur variabel penelitian, walaupun dilakukan secara berulang-ulang dengan angket atau kuesioner yang sama.

Analisis inferensial pada penelitian ini menggunakan menggunakan metode Smart PLS (VB-SEM) dengan tujuan untuk mengurangi kelemahan-kelemahan yang mengurangi komprehensifitas dari analisis. Seperti asumsi-asumsi yang harus diperiksa oleh peneliti untuk memastikan bahwa persamaan regresi yang dibentuk BLUE (Best Linier Unbiased Estimate) salah satunya adalah asumsi normalitas. (Henseler dan Chin, 2010) mengutarakan bahwa pada penelitian bisnis dan manajemen yang melakukan pengukuran persepsi akan sulit untuk mendapatkan data yang berdistribusi normal sehingga peneliti akan sulit untuk mendapatkan persamaan regresi yang BLUE. Sedangkan pada PLS menggunakan metode Bootstraping atau penggandaan iterasi secara acak sehingga asumsi normalitas tidak akan menjadi masalah bagi PLS.

Berdasarkan asumsi secara statistik, PLS digolongkan sebagai jenis analisis non-parametrik hal ini berbeda jika dibandingkan dengan covariance based SEM (CB-SEM) seperti Amos dan Lisrel yang termasuk ke dalam analisis parametrik atau multivariate normal distribution. Selain itu PLS tidak mensyaratkan jumlah minimum sample sehingga penelitian yang menggunakan jumlah sample kecil dapat menggunakan PLS mengingat PLS berbasis variance sehingga dapat menggunakan jumlah sample kecil berkisar 30100 namun akan semakin baik jika jumlah sample semakin banyak. Secara lebih sistematis, peneliti menggambarkan alur analisis pada penelitian ini sebagai berikut:

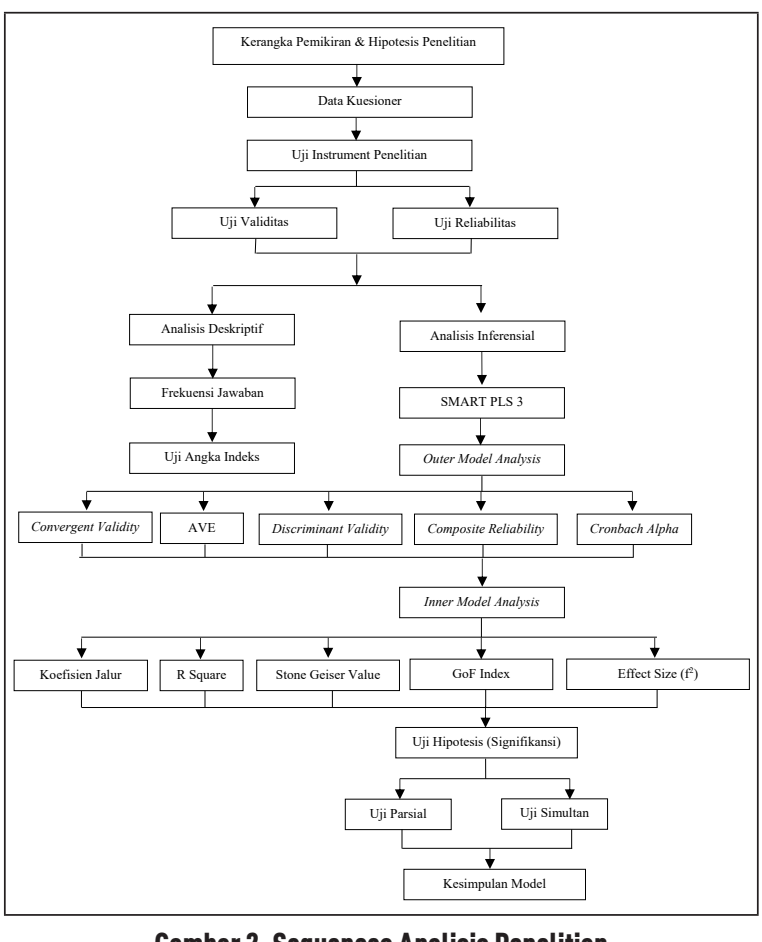

Gambar 2. Sequences Analisis Penelitian 


\section{HASIL dan PEMBAHASAN}

Hasil uji validitas dengan menggunakan SPSS Versi 22 didapatkan nilai signifikansi untuk masing-masing indikator memiliki nilai dibawah 0,05 yang menggambarkan item indikator valid dan dapat menjelaskan masing-masing variabel yang diukur sebagaimana terangkum pada tabel berikut:

\begin{tabular}{|c|c|c|c|}
\hline Variabel & Indikator & Signifikansi & Kesimpulan \\
\hline \multirow{4}{*}{$\begin{array}{c}\text { Dimensi } \\
\text { Struktural }\end{array}$} & S1 & 0,000 & Valid \\
\hline & S2 & 0,000 & Valid \\
\hline & S3 & 0,000 & Valid \\
\hline & 54 & 0,000 & Valid \\
\hline \multirow{5}{*}{$\begin{array}{c}\text { Dimensi } \\
\text { Relasional }\end{array}$} & R1 & 0,000 & Valid \\
\hline & R2 & 0,000 & Valid \\
\hline & R3 & 0,000 & Valid \\
\hline & R4 & 0,000 & Valid \\
\hline & R5 & 0,000 & Valid \\
\hline \multirow{3}{*}{$\begin{array}{l}\text { Dimensi } \\
\text { Kognitif }\end{array}$} & K1 & 0,000 & Valid \\
\hline & K2 & 0,000 & Valid \\
\hline & K3 & 0,000 & Valid \\
\hline \multirow{5}{*}{ Kinerja Dosen } & KD1 & 0,000 & Valid \\
\hline & KD2 & 0,000 & Valid \\
\hline & KD3 & 0,000 & Valid \\
\hline & KD4 & 0,000 & Valid \\
\hline & KD5 & 0,000 & Valid \\
\hline
\end{tabular}

Hasil Uji reliabilitas terhadap masing-masing item indikator dengan menggunakan SPSS Versi 22, didapatkan nilai Alpha Cronbach's untuk masing-masing indikator lebih besar dari 0,60 yang menggambarkan bahwa item indikator memiliki reliabilitas yang handal, sebagaimana terangkum pada tabel berikut:

\begin{tabular}{c|c|c|c|}
\multicolumn{3}{c}{ Tabel 3. Hasil Uji Reliabilitas Menggunakan SPSS Versi 22} \\
Variabel & Indikator & Alpha Cronbach's & Kesimpulan \\
\cline { 2 - 4 } $\begin{array}{c}\text { Dimensi } \\
\text { Struktural }\end{array}$ & S1 & 0,749 & Reliabel \\
\cline { 2 - 4 } & S2 & 0,656 & Reliabel \\
\cline { 2 - 4 } & S3 & 0,764 & Reliabel \\
\hline \multirow{4}{*}{$\begin{array}{c}\text { Dimensi } \\
\text { Relasional }\end{array}$} & S4 & 0,772 & Reliabel \\
\cline { 2 - 4 } & R1 & 0,869 & Reliabel \\
\cline { 2 - 4 } & R2 & 0,870 & Reliabel \\
\cline { 2 - 4 } & R4 & 0,887 & Reliabel \\
\hline \multirow{4}{*}{$\begin{array}{c}\text { Dimensi } \\
\text { Kognitif }\end{array}$} & K1 & 0,861 & Reliabel \\
\cline { 2 - 4 } & K2 & 0,866 & Reliabel \\
\cline { 2 - 4 } & K3 & 0,733 & Reliabel \\
\hline
\end{tabular}

\begin{tabular}{|c|c|c|c|}
\hline \multirow{4}{*}{ Kinerja Dosen } & KD1 & 0,881 & Reliabel \\
\cline { 2 - 4 } & KD2 & 0,884 & Reliabel \\
\cline { 2 - 4 } & KD3 & 0,851 & Reliabel \\
\cline { 2 - 4 } & KD4 & 0,872 & Reliabel \\
\cline { 2 - 4 } & KD5 & 0,872 & Reliabel \\
\hline
\end{tabular}

Hasil uji deskriptif terhadap 58 responden terhadap dimensi struktural didapatkan angka indeks untuk masing-masing indikator berada pada ketgori tinggi, indikator S1 memiliki angka indeks $84,40 \%$, indikator S2 sebesar $87,60 \%$, indikator S3 sebesar $86,40 \%$ dan indikator S4 sebesar $82,00 \%$. Dari angka indeks tersebut menunjukkan indikator S2 yaitu memenuhi tanggung jawab sesuai dengan job deskripsi memiliki nilai respon yang paling tinggi sebesar $87,60 \%$, sedangkan nilai angka indeks rata-rata keempat indikator didapatkan sebesar 85,05\%.

Hasil uji deskriptif dimensi relasional didapatkan angka indeks untuk masing-masing indikator berada pada kategori tinggi, indikator R1 memiliki angka indeks sebesar $88,00 \%$, indikator R2 sebesar $89,60 \%$, indikator R3 sebesar $86,80 \%$, indikator $\mathrm{R} 4$ sebesar $86,80 \%$ dan indikator R4 sebesar $88,80 \%$. Dari angka indeks tersebut menunjukkan indikator R2 yaitu bersedia meluangkan waktu untuk membantu rekan kerja menjadi indikator dengan respon tertinggi sebesar $89,60 \%$, sedangkan nilai angka indeks ratarata kelima indikator sebesar $88,00 \%$.

Hasil uji deskriptif dimensi kognitif didapatkan angka indeks untuk masing-masing indikator berada pada kategori tinggi, indikator $\mathrm{K} 1 \mathrm{memi}-$ liki angka indeks sebesar $86,00 \%$, indikator K2 sebesar 88,40\% dan indikator K3 sebesar 85,60\%. Dari angka indeks tersebut menunjukkan indikator K2 yaitu setiap tindak berusaha untuk menghindari konflik memiliki angka indeks tertinggi sebesar $88,40 \%$, sedangkan nilai angka indeks rata-rata ketiga indikator sebesar 86,67\%.

Hasil uji deskriptif variabel kinerja dosen menunjukkan kategori tinggi untuk kelima indikator, dimana indikator KD1 memiliki angka indeks sebesar 78,40\%, indikator KD2 sebesar $82,40 \%$, indikator KD3 sebesar $76,40 \%$, indikator KD4 sebesar 75,20\% dan indikator KD5 sebesar $76,80 \%$. Dari angka indeks tersebut menunjukkan indikator indikator KD2 yaitu loyalitas memiliki 
angka indeks tertinggi sebesar $82,40 \%$, dengan nilai rata-rata angka indeks untuk kelima indi- kator tersebut sebesar 77,84\%. Untuk lebih detail hasil uji deskriptif dapat dilihat pada tabel berikut:

\begin{tabular}{|c|c|c|c|c|c|c|c|c|c|}
\hline \multirow{2}{*}{ Variabel } & \multirow{2}{*}{ Indikator } & \multicolumn{5}{|c|}{ Frekuensi Jawaban } & \multirow{2}{*}{ Jumlah } & \multirow{2}{*}{ Angka Indeks } & \multirow{2}{*}{$\begin{array}{l}\text { Rata-Rata } \\
\text { Angka Indeks }\end{array}$} \\
\hline & & 1 & 2 & 3 & 4 & 5 & & & \\
\hline \multirow[t]{4}{*}{$\begin{array}{c}\text { Dimensi } \\
\text { Struktural }\end{array}$} & S1 & 0 & 1 & 24 & 28 & 5 & 58 & $84,40 \%$ & \multirow{4}{*}{$85,05 \%$} \\
\hline & S2 & 0 & 1 & 20 & 28 & 9 & 58 & $87,60 \%$ & \\
\hline & S3 & 0 & 3 & 12 & 41 & 2 & 58 & $86,40 \%$ & \\
\hline & S4 & 0 & 1 & 28 & 26 & 3 & 58 & $82,00 \%$ & \\
\hline \multirow[t]{5}{*}{$\begin{array}{c}\text { Dimensi } \\
\text { Relasional }\end{array}$} & R1 & 0 & 1 & 17 & 33 & 7 & 58 & $88,00 \%$ & \multirow{5}{*}{$88,00 \%$} \\
\hline & R2 & 0 & 2 & 14 & 32 & 10 & 58 & $89,60 \%$ & \\
\hline & R3 & 0 & 4 & 16 & 29 & 9 & 58 & $86,80 \%$ & \\
\hline & R4 & 0 & 5 & 13 & 32 & 8 & 58 & $86,80 \%$ & \\
\hline & R5 & 0 & 3 & 15 & 29 & 11 & 58 & $88,80 \%$ & \\
\hline \multirow[t]{3}{*}{ Dimensi Kognitif } & K1 & 0 & 3 & 17 & 32 & 6 & 58 & $86,00 \%$ & \multirow{3}{*}{$86,67 \%$} \\
\hline & K2 & 0 & 1 & 18 & 30 & 9 & 58 & $88,40 \%$ & \\
\hline & K3 & 0 & 1 & 23 & 27 & 7 & 58 & $85,60 \%$ & \\
\hline \multirow[t]{5}{*}{ Kinerja Dosen } & KD1 & 0 & 9 & 24 & 19 & 6 & 58 & $78,40 \%$ & \multirow{5}{*}{$77,84 \%$} \\
\hline & KD2 & 0 & 5 & 24 & 21 & 8 & 58 & $82,40 \%$ & \\
\hline & KD3 & 0 & 8 & 25 & 25 & 0 & 58 & $76,40 \%$ & \\
\hline & KD4 & 0 & 11 & 22 & 25 & 0 & 58 & $75,20 \%$ & \\
\hline & KD5 & 0 & 5 & 30 & 23 & 0 & 58 & $76,80 \%$ & \\
\hline
\end{tabular}

Hasil uji outer analysis menggunakan convergent validity didaatkan nilai loading faktor untuk dimensi struktural sebagai berikut, indikator S1 sebesar 0,771, indikator S2 sebesar 0,882, indikator S3 sebesar 0,713, dan indikator S4 sebesar 0,758. Dari hasil tersebut menunjukkan bahwa seluruh item indikator memiliki nilai loading faktor diatas 0,70 sehingga dikatakan valid. Hasil loading faktor untuk dimensi relasional didapatkan nilai loading faktor untuk indikator R1 sebesar 0,846, indikator R2 sebesar 0,837, indikator R3 sebesar 0,787 , indikator R4 sebesar 0,875 dan indikator R5 sebesar 0,854. Dari hasil tersebut menunjukkan bahwa seluruh item indikator memiliki nilai loading faktor diatas 0,70 sehingga dikatakan valid. Hasil loading faktor untuk dimensi kognitif didapatkan nilai loading faktor untuk indikator $\mathrm{K} 1$ sebesar 0,839 , indikator K2 sebesar 0,870 dan indikator K3 sebesar 0,816. Dari hasil loading faktor tersebut menunjukkan seluruh item indikator memiliki nilai loading faktor di atas 0,70 sehingga dikatakan valid. Hasil loading faktor untuk variabel kinerja dosen didapatkan nilai loading faktor untuk indikator
KD1 sebesar 0,808, indikator KD2 sebesar 0,806 , indikator $\mathrm{KD} 3$ sebesar 0,920 , indikator KD4 sebesar 0,838 dan indikator KD5 sebesar 0,864. Dari hasil tersebut menunjukkan seluruh indikator untuk variabel kinerja dosen memiliki nilai loading faktor di atas 0,70 sehingga dikatakan valid. Hasil tersebut menunjukkan bahwa seluruh item indikator mampu mewakili dan menjelaskan variabel laten yang dibangunnya.

Hasil uji Average Variance Extracted terhadap masing-masing variabel laten didapatkan nilai AVE untuk dimensi struktural sebesar 0,614, dimensi relasional sebesar 0,706 , dimensi kognitif sebesar 0,708 dan variabel kinerja dosen sebesar 0,719. Hasil tersebut menunjukkan nilai AVE untuk keempat variabel laten lebih besar dari 0,50 yang menggambarkan bahwa nilai varians dari masing-masing indikator dalam konstruk yang ditangkap oleh variabel tersebut lebih besar dibandingkan dengan nilai varians yang diakibatkan oleh kesalahan pengukuran.

Hasil uji discriminant validity terhadap seluruh item indikator dari masing-masing variabel menunjukkan nilai loading faktor untuk masing- 
masing indikator lebih besar dibandingkan dengan nilai cross loadingnya. Hasil tersebut menunjukkan bahwasanya indikator mampu menjadi variabel manifest yang valid bagi konstruknya.

Hasil uji komposit reliability terhadap masing-masing variabel laten didapatkan nilai $\mathrm{CR}$ untuk dimensi struktural sebesar 0,863 , nilai CR untuk dimensi relasional sebesar 0,923, nilai CR untuk dimensi kognitif sebesar 0,879 dan untuk variabel kinerja dosen sebesar 0,927. Hasil ini menunjukkan nilai CR keempat variabel di atas 0,70 sehingga dapat dikatakan indikator memiliki konsistensi yang handal untuk mengukur konstruk yang dibangunnya.

Hasil uji Alpha Cronbach's terhadap masingmasing variabel laten didapatkan nilai sebesar 0,789 untuk dimensi struktural, 0,896 untuk dimensi relasional, 0,794 untuk dimensi kognitif dan 0,902 untuk dimensi kinerja dosen. Hasil ini menunjukkan nilai Alpha Cronbach's untuk keempat variabel berada di atas 0,60 sehingga dapat dikatakan bahwa indikator memiliki konsistensi yang handal untuk mengukurr konstruk yang dibangunnya. Hasil Alpha Cronbach's ini memperkuat reliabilitas dari masing-masing indikator yang sebelumnya telah diukur dengan menggunakan nilai komposit reliability (CR).

Hasil pengujian Goodness of Fit (GoF) dari outer moel analysis di atas menunjukkan hasil yang sangat baik, dimana seluruh kriteria berhasil terpenuhi. Oleh karena itu analisis dapat dilanjutkan ketahap berikutnya yaitu pengujian struktural (inner model analysis) dengan menggunakan lima kriteria pengujian yaitu nilai koefisien jalur, nilai $R$ square $\left(\mathrm{R}^{2}\right)$, nilai stone giesser $\left(\mathrm{Q}^{2}\right)$, GoF indeks dan Effect size ( $\left.\mathrm{f}^{2}\right)$.

Hasil analisis Bootsrapping model diapatkan nilai koefisien jalur untuk dimensi struktural sebesar 0,242 , sedangkan untuk dimensi relasional sebesar 0,319 dan dimensi kognitif sebesar 0,359. Fdari hasil koefisien jalur ini didapatkan bahwasanya pengaruh dimensi struktural, relasional dan kognitif terhadap kinerja dosen adalah positif. Hal ini menggambarkan semakin tinggi dimensi struktural, relasional dan kognitif maka akan meningkatkan kinerja dosen. Bentuk persamaan pada model yang dibangun adalah $\mathrm{KD}=0,242 \mathrm{~S}+$
$0,319 \mathrm{R}+0,359 \mathrm{~K}+\mathrm{e}$

Nilai $R$ Square dari model penelitian yang telah dianalisa menggunakan PLS Algorithm didapatkan sebesar 0,728 sehingga besarnya pengaruh variabel eksogen terhadap endogen secara bersama-sama didapatkan sebesar $72,80 \%$. Hasil ini menggambarkan bahwasanya dimensi struktural, dimensi relasional dan dimensi kognitif memiliki pengaruh sebesar $72,80 \%$ terhadap kinerja dosen. Sedangkan sisanya sebesar 27,20\% dipengaruhi variabel diluar model penelitian ini.

Hasil analisis PLS Blindfolding didapatkan construct crossvalidated redundancy berupa nilai $\mathrm{Q}^{2}$ sebesar 0,469. Nilai $\mathrm{Q}^{2}$ ini menggambarkan predictive relevance yaitu kecocokan model secara struktural. Nilai $\mathrm{Q}^{2}>0$ menggambarkan bahwa model memiliki predictive relevance yang baik artinya masing-masing variabel prediktor mampu memprediksi dari variabel laten yang dibangunnya.

Uji kecocokan model dengan menggunakan Goodness of Fit Index (GoF) menggambarkan kecocokan model secara keseluruhan, baik untuk outer model maupun untuk inner model dan dihitung secara manual dengan menggunakan rumus sebagai berikut:

$$
G o F=\sqrt{\overline{A V E}} x \overline{R^{2}}
$$

Dimana nilai AVE adalah variance extracted communality dan nilai $\mathrm{R}^{2}$ adalah nilai $\mathrm{R}^{2}$ ratarata dari model yang diprediksi.dari hasil analisis Algorithm didapatkan nilai AVE communality sebesar 0,687 sedangkan nilai $\mathrm{R}^{2}$ sebesar 72,8 sehingga didapatkan nilai GoF sebesar 0,707. Menurut Tenenhau (2004), rentang nilai GoF Index terbagi menjadi pada 3 kategori yaitu 0.00 0.24 kategori kecil, 0.25-0.37 kategori sedang dan 0.38-1.00 kategori tinggi. Sehingga dapat disimpulkan dengan nilai GoF index sebesar 0,707 maka model masuk kedalam kategori tinggi, artinya model penelitian yang dibangun memiliki kecocokan yang tinggi atau tidak terdapat perbedaan (discrepancy) antara nilai yang diobservasi dengan nilai-nilai yang diharapkan di dalam model penelitian.

Effect size digunakan untuk menggambarkan 
besarnya effect secara partial dari variabel laten eksogen terhadap variabel endogen pada tatanan structural. Besarnya effect size diukur dengan menggunakan $\mathrm{f}^{2}$ dimana dalam perhitungan nilai $\mathrm{f}^{2}$ diperlukan nilai $\mathrm{R}^{2}$ model secara keseluruhan ( $\mathrm{R}^{2}$ included) dan $\mathrm{R}^{2}$ excluded atau $\mathrm{R}^{2}$ pada saat variabel laten yang diukur tidak dimasukkan. Chin (2013) membagi $\mathrm{f}^{2}$ ke dalam 3 kategori antara lain 0.00-0,20 kategori small effect, 0.21-0.50 kategori moderat effect dan 0.51-1.00 kategori strong effect. Hasil analisis didapatkan nilai $\mathrm{f} 2$ untuk dimensi struktural sebesar 0,076, dimensi relasional sebesar 0,092 dan dimensi kognitif sebesar 0,146. Hasil ini menunjukkan effect size berada pada rentang nilai $0,00-0,20$ sehingga ketiga dimensi modal sosial memiliki effect size small terhadap kinerja dosen.

Hasil uji hipotesis secara parsial didapatkan nilai T Statistic untuk dimensi struktural sebesar 2,101 dengan nilai sig 0,036. Dimensi relasional memiliki T Statistic sebesar 2,114 dengan nilai sig 0,035 dan TStatistic untuk dimensikognitif sebesar 2,989 dengan sig 0,003 . Hasil ini menunjukkan bahwa ketiga dimensi memiliki nilai T Statistic > dari Z-Score 1,96 yang menggambarkan bahwa terdapat pengaruh secara parsial yang signifikan antara dimensi struktural, dimensi relasional dan dimensi kognitif terhadap kinerja dosen.

Untuk melakukan pengujian hipotesis secara parsial, maka digunakan rumus sebagai berikut yang kemudian dibandingkan dengan nilai $\mathrm{F}$ tabel.

$$
\begin{aligned}
& \text { Fhit }=\frac{R^{2} / k}{\left(1-R^{2}\right) /(N-k-1)} \\
& \text { Fhit }=\frac{0.728 / 3}{(1-0.728) /(58-3-1)} \\
& \text { Fhit }=\frac{0.2427}{(1-0.728) /(58-3-1)} \\
& \text { Fhit }=\frac{0.2427}{0.0050} \\
& \text { Fhit }=48.54
\end{aligned}
$$

Hasil perhitungan uji $\mathrm{F}$ didapatkan nilai $\mathrm{F}_{\text {hitung }}$ sebesar 48,54 dimana nilai tersebut lebih besar dibandingkan dengan nilai $\mathrm{F}_{\text {tabel }}$ pada alpha $5 \%$ dan df $2=54(\mathrm{~N}-\mathrm{k})$ dimana $\mathrm{N}$ adalah jumlah sampel dan k adalah jumlah variabel independen, sehingga didapatkan nilai $\mathrm{F}_{\text {tabel }}$ sebesar 2,77. Hasil ini menggambarkan bahwa terdapat pengaruh positif dan signifikan antara dimensi struktural, dimensi relasional dan dimensi kognitif secara simultan terhadap kinerja dosen pada perguruan tinggi swasta di Kota Serang.

Hasil penelitian menunjukkan kesamaan hasil jika dibandingkan dengan penelitian sebelumnya, baik dengan penelitian Astuti (2012), Edy et al. (2013), Khoirrini \& Kartika (2016), Tjahjaningsih (2016), Ghifary (2017), Hartono (2017) dan Bangsri et al. (2018) dimana ketiga dimensi modal sosial berpengaruh signifikan terhadap kinerja pegawai. Sehingga modal sosial merupakan suatu keunggulan kompetitif yang harus dijaga oleh suatu organisasi sebagai aset berharga. Dengan meningkatkan modal sosial maka organisasi akan mampu membuat perbedaan dibandingkan dengan organisasi lainnya. Dimana interaksi sosial ini akan menjadi sesatu yang sangat sulit ditiru oleh organisasi lainnya.

\section{SIMPULAN}

Berdasarkan hasil uji kesesuain model dengan menggunakan outer model analysis dengan menggunakan uji konvergen validitas, AVE, discriminant validitas, komposit reliability dan Alpha cronbach's didapatkan nilai untuk masingmasing uji berada diatas cut off value sehingga disimpulkan bahwa model penelitian memiliki goodness of fit yang baik sehingga model penelitian dapat diteruskan untuk dilakukan pengujian inner model analysis. Hasil inner model analysis didapatkan bahwa nilai koefisien jalur memiliki nilai positif untuk setiap variabel eksogen terhadap variabel endogen. Nilai $R$ square $\left(\mathrm{R}^{2}\right)$ diapatkan sebesar 0,728 dimana nilai ini menggambarkan besarnya pengaruh variabel eksogen terhadap variabel endogen sebesar $72,80 \%$ sedangkan sisanya sebesar $27,20 \%$ dipengaruhi variabel lainnya diluar model penelitian ini. Nilai stone giesser $\left(\mathrm{Q}^{2}\right)$ didapatkan sebesar 0,469 dimana nilai ini $>0$ sehingga dikatakan model penelitian memiliki relefansi yang baik dalam menghasilkan prediksi terhadap variabel endogen. GoF indeks 
didapatkan sebesar 0,707 dimana nilai ini masuk kedalam kategori tinggi. Sedangkan untuk Effect size $\left(\mathrm{f}^{2}\right)$ ketiga variabel dari dimensi modal sosial terhadap kinerja dosen memiliki effect size small.

Hasil uji hipotesis secara parsial didapatkan nilai $\mathrm{T}$ Statistic untuk dimensi struktural sebesar 2,101 dengan nilai sig 0,036. Dimensi relasional memiliki T Statistic sebesar 2,114 dengan nilai sig 0,035 dan T Statistic untuk dimensi kognitif sebesar 2,989 dengan sig 0,003. Hasil ini menunjukkan bahwa ketiga dimensi memiliki nilai T Statistic > dari Z-Score 1,96 yang menggambarkan bahwa terdapat pengaruh secara parsial yang signifikan antara dimensi struktural, dimensi relasional dan dimensi kognitif terhadap kinerja dosen. Hasil perhitungan uji $\mathrm{F}$ didapatkan nilai $\mathrm{F}_{\text {hitung }}$ sebesar 48,54 dimana nilai tersebut lebih besar dibandingkan dengan nilai $\mathrm{F}_{\text {tabel }} 2,77$ pada alpha 5\% dan $\mathrm{df}_{2}=54(\mathrm{~N}-\mathrm{k})$. Berdasarkan hasil uji hipotesis dapat disimpulkan bahwa seluruh hipotesis yang telah diformulasikan pada penelitian ini diterima.

Penelitian ini diharapkan dapat memberikan kontribusi bagi pemikiran dan pengayaan dalam ilmu bidang manajemen khususnya kajian manajemen sumber daya manusia. Sedangkan manfaat praktis diharapkan dapat menjadi acuan bagi para pimpinan perguruan tinggi terhadap filosofi pengelolaan sumber daya manusia di perguruan tinggi. Namun penelitian ini masih terdapat kekurangan seperti minimnya jumlah sampel mengingat setiap perguruan tinggi memiliki jumlah dosen tetap yang bervariasi bergantung kepada rasio jumlah mahasiswanya, sehingga untuk penelitian selanjutnya dapat dijadikan sebagai bahan evaluasi dan pengembangan seperti dilakukannya pengujian lintas perguruan tinggi dan lain sebagainya.

\section{PENGHARGAAN}

Puji syukur yang mendalam dan ucapan terima kasih yang sebesar-besarnya atas sumbangsih dari berbagai pihak selama penulis menjalankan proses pembelajaran pada Program Studi Doktoral Manajemen (PSDM) Universitas Mercu Buana sekaligus juga penelitian ini. Terutama kepada Prof. Dr. Masyhudzulhak Djamil, SE, MM., Dr. Achmad H. Sutawidjaya, M.Com, M.Phill, CSCP, ASCA, CIMP dan Dr. Ahmad Badawi Saluy, SE. MM. CHRA atas bimbingannya selama ini sekaligus juga sebagai motivator yang dengan sifat keayahannya senantiasa mendorong penulis untuk terus maju. Harapan dan doa penulis, semoga seluruh sumbangsih yang telah dikeluarkan dapat menjadi ladang amal dan cahaya serta berhasil menjadi ahli surga kelak. Amin.

\section{DAFTAR PUSTAKA}

Abbasi, A., \& Malik, A. (2015). International Journal of Economics and Financial Issues Firms' Size Moderating Financial Performance in Growing Firms: An Empirical Evidence from Pakistan. International Journal of Economics and Financial Issues, 5(2), 334339. Retrieved from http:www.econjournals. com.

Astuti, S. R. (2012). Pengaruh Modal Sosial Dimensi Relasional, Modal Sosial Dimensi Struktural, Dan Motivasi Terhadap Kinerja In-Role Dan Ex-Role Karyawan "Koperasi Karyawan Angkasa Pura I (Kokapura Avia) Ground Handling." Jurnal Manajemen, 2(1), 49-58.

Bangsri, K., Jepara, K., Fanbellisa, S., Satmoko, S., Dalmiyatun, T. (2018). Pengaruh Modal Sosial Terhadap Keberlanjutan Gapoktan Sumber Mulyo Di Desa Banjaran. Universitas Diponegoro Semarang, 1-13.

Chua, A. (2002). The influence of social interaction on knowledge creation. Journal of Intellectual Capital, 3(4), 375-392. https:// doi.org/10.1108/14691930210448297.

Edy, Y. J., Maupa, H., \& Edy, H. J. (2013). Pengaruh Modal Sosial Dan Budaya Organisasi Kepulauan Talaud. Jurnal Ilmiah Farmasi, 2(03), 19-23.

Endang Tjahjaningsih, C. C. (2016). Pengaruh Employee Engagement Dan Modal Sosial Terhadap Kinerja Karyawan Dengan OCB (Organizational Citizenship Behaviour) Sebagai Mediasi (Studi pada Bank Jateng Kantor Pusat). Media Ekonomi Dan 
Manajemen, 30(2), 149-160. https://doi. org/10.24856/mem.v30i2.242.

Ferdinand, A. (2013). Metodologi Penelitian Manajemen. Semarang: Universitas Diponegoro.

Ghifary, M. T. (2017). DIMENSI SOCIAL CAPITAL YANG MEMENGARUHI in Health BPJS. Jurnal MKMI, 13(2), 116-124.

Hair, J. F., Sarstedt, M., Hopkins, L., \& Kuppelwieser, V. G. (2014). Partial least squares structural equation modeling (PLSSEM): An emerging tool in business research. European Business Review, 26(2), 106-121. https://doi.org/10.1108/EBR-10-2013-0128.

Hartono, T. (2017). Pengaruh Dimensi-Dimensi Modal Sosial Terhadap Kinerja Individu Mahasiswa-mahasiswi Guild Family Business Universitas Ciputra. 2.

Henseler, J., \& Chin, W. W. (2010). A comparison of approaches for the analysis of interaction effects between latent variables using partial least squares path modeling. Structural Equation Modeling, 17(1), 82-109. https:// doi.org/10.1080/10705510903439003.

Khoirrini, L., \& Kartika, L. (2016). Pengaruh Modal Insani dan Modal Sosial terhadap Kinerja (Studi Kasus Usaha Kecil dan Menengah (UKM) Makanan dan Minuman Kota Bogor). Jurnal Manajemen Dan Organisasi, 5(3), 244. https://doi.org/10.29244/jmo.v5i3.12174.

Mangkunegara, A. P. (2001). Manajemen Sumber Daya Manusia Perusahaan. Bandung: Rosdakarya.

Muniady, R. Al, Mamun, A. Al, Rosli Mohamad, M., Yukthamarani Permarupan, P., \& Binti Zainol, N. R. (2015). The effect of cognitive and relational social capital on structural social capital and micro-enterprise performance. SAGE Open, 5(4). https://doi. org/10.1177/2158244015611187.

Nahapiet, J., \& Ghoshal, S. (1998). Social Capital , Intellectual Capital , and the Organizational Advantage Janine Nahapiet; Sumantra Ghoshal. The Academy of Management Review, 23(2), 242-266. https://doi. org/10.2307/259373.

Oliveira, J. F \& Wegner, D. (2013). The Influenece of Social Capital On Business Performance: An Analysis In The Context of Horizontal Business Network. Revista de Administração Mackenzie, 14(3), 209-235.

Pramudyo, A. (2010). Analisis Faktor-Faktor Yang Mempengaruhi Kinerja Dosen Negeri Pada Kopertis Wilayah V Yogyakarta. Jurnal Bisnis : Teori Dan Implementasi, 1(1), 1-11. Retrieved from http://journal.umy.ac.id/ index.php/bti/article/view/2407.

Pratisthita. (2014). Peran Modal Sosial Dalam Menunjang Dinamika Kelompok Peternak Sapi Perah (Studi Kasus di Kelompok 3 TPK Pulosari Pangalengan). Jurnal Ilmu Ternak, 14(1).

Putnam. (1993). The Prosperous Community: Social Capital and Public Life. American Prospect. Massachusetts: Edward Elgar Publishing.

Simamora, H. (2014). Manajemen Sumber Daya Manusia. Yogyakarta: Bagian Penerbitan Sekolah Tinggi Ilmu Ekonomi YKPN.

Simanjuntak, P. (2005). Manajemen Dan Evaluasi Kinerja. Jakarta: FE UI.

Supriadi, et al. (2019). Pengaruh Motivasi Kerja Dan Kepemimpinan Terhadap Kinerja Dosen STMIK Kharisma Karawang. Jurnal Manajemen \& Bisnis Kreatif, 4(2), 43-65.

Undang-Undang Republik Indonesia No. 14 Tahun 2005. Tentang Guru dan Dosen. 